\title{
Comparative analysis of the complete chloroplast genome sequences in psammophytic Haloxylon species (Amaranthaceae)
}

\author{
Wenpan Dong ${ }^{1,2}$, Chao Xu ${ }^{1,3}{ }^{\text {, Delu Li }}{ }^{4}$, Xiaobai Jin ${ }^{5}$, Ruili Li ${ }^{5}$, Qi Lu ${ }^{\text {Corresp.. }}{ }^{6}$, Zhili Suo ${ }^{\text {Corresp. } 1}$ \\ ${ }^{1}$ State Key Laboratory of Systematic and Evolutionary Botany, Institute of Botany, Chinese Academy of Sciences, 20 Nanxincun, Haidian District, Beijing \\ 100093, China \\ 2 Peking-Tsinghua Center for Life Sciences, Academy for Advanced Interdisciplinary Studies, Peking University, 5 Yiheyuan Road Haidian District, Beijing \\ 100871, China \\ 3 University of Chinese Academy of Sciences, 19 A Yuquan Road, Shijingshan District, Beijing 100049, China \\ 4 Gansu Desert Control Research Institute, 390 Beibinhe West Road, Anning District, Lanzhou, Gansu 730070, China \\ 5 Beijing Botanical Garden, Institute of Botany, Chinese Academy of Sciences, 20 Nanxincun, Haidian District, Beijing 100093, China \\ 6 Institute of Desertification Studies, Chinese Academy of Forestry, 10, Huai-shu-ju Road, Haidian District, Beijing 100091, China \\ Corresponding Authors: Qi Lu, Zhili Suo \\ Email address: Luqi@caf.ac.cn, zlsuo@ibcas.ac.cn
}

The Haloxylon genus belongs to the Amaranthaceae (formerly Chenopodiaceae) family. The small trees or shrubs in this genus are referred to as the King of psammophytic plants, and perform important functions in environmental protection, including wind control and sand fixation in deserts. To better understand these beneficial plants, we sequenced the chloroplast (cp) genomes of Haloxylon ammodendron (HA) and Haloxylon persicum (HP) and conducted comparative genomic analyses on these and two other representative Amaranthaceae species. Similar to other higher plants, we found that the Haloxylon cp genome is a quadripartite, double-stranded, circular DNA molecule of 151,570 bp in HA and $151,586 \mathrm{bp}$ in HP. It contains a pair of inverted repeats $(24,171 \mathrm{bp}$ in HA and 24,177 bp in HP) that separate the genome into a large single copy region of 84,214 bp in HA and 84,217 bp in HP, and a small single copy region of 19,014 bp in HA and 19,015 bp in HP. Each Haloxylon cp genome contains 112 genes, including 78 coding, 30 tRNA, and four ribosomal RNA genes. We detected 59 different simple sequence repeat loci, including 44 mono-nucleotide, three di-nucleotide, one tri-nucleotide, and 11 tetra-nucleotide repeats. Comparative analysis revealed only 67 mutations between the two species, including 44 substitutions, 23 insertions/deletions, and two micro-inversions. The two inversions, with lengths of 14 and $3 \mathrm{bp}$, occur in the petA-psb/ intergenic region and rp/16 intron, respectively, and are predicted to form hairpin structures with repeat sequences of 27 and $19 \mathrm{bp}$, respectively, at the two ends. The ratio of transitions to transversions was 0.76. These results are valuable for future studies on Haloxylon genetic diversity and will enhance our understanding of the phylogenetic evolution of Amaranthaceae. 
1 Comparative analysis of the complete chloroplast genome sequences in

2 psammophytic Haloxylon species (Amaranthaceae)

3

4

\section{Wenpan Dong ${ }^{1,2}$, Chao Xu1, ${ }^{1,3}$, Delu Li ${ }^{4}$, Xiaobai Jin ${ }^{5}$, Ruili Li ${ }^{5}$, Qi Lu ${ }^{6, *}$, Zhili Suo ${ }^{1, *}$}

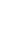

(1)

${ }^{1}$ State Key Laboratory of Systematic and Evolutionary Botany, Institute of Botany, Chinese Academy of Sciences, 20 Nanxincun, Haidian District, Beijing 100093, China

E-mail: wpdong@ibcas.ac.cn (W.P.D.); xuchao@ibcas.ac.cn (X.C.)

${ }^{2}$ Peking-Tsinghua Center for Life Sciences, Academy for Advanced Interdisciplinary Studies, Peking University, 5 Yiheyuan Road Haidian District, Beijing 100871, China

${ }^{3}$ University of Chinese Academy of Sciences, 19 A Yuquan Road, Shijingshan District, Beijing 100049, China

${ }^{4}$ Gansu Desert Control Research Institute, 390 Beibinhe West Road, Anning District, Lanzhou, Gansu 730070, China

E-mail: lidlu2008@163.com

${ }^{5}$ Beijing Botanical Garden, Institute of Botany, Chinese Academy of Sciences, 20 Nanxincun, Haidian District, Beijing 100093, China

E-mail: jinxiaobai@ibcas.ac.cn

E-mail: 1irl@ibcas.ac.cn, 20778033@qq.com

${ }^{6}$ Institute of Desertification Studies, Chinese Academy of Forestry, 10, Huai-shu-ju Road, Haidian District, Beijing 100091, China

*Correspondence: zlsuo@ibcas.ac.cn; Tel.: 861013520435137

Luqi@caf.ac.cn; $\quad$ Tel.: 861013910830860 


\section{ABSTRACT}

32

\section{INTRODUCTION}

54 The eudicot clade comprises approximately $75 \%$ of all flowering land plant species, including major subclades: 
55

56

57

58

59

60

61

62

rosids, asterids, Saxifragales, Santalales, and Caryophyllales (APG III, 2009). Haloxylon species, which include psammophytic small trees or shrubs, are positioned phylogenetically in the Amaranthaceae Juss of the Caryophyllales Perleb among core eudicots (APG III, 2009; Pyankov et al., 2001; Akhani et al., 2007). The Haloxylon genus has about 11 species, with a distribution from the Mediterranean through Central Asia and into China (Zhu et al., 2004). Two Haloxylon species, which are known as the King of psammophytic plants, are found in the deserts of northwest China and, play important roles in environmental protection, including wind control and sand fixation (Zhu et al., 2004; Jia \& Lu, 2004). These precious psammophytic woody plants can adapt to harsh environmental conditions, such as drought, desert, high temperature, and sand storms. However, populations of Haloxylon plants have been threatened in China in past decades as a result of decreased underground water, overgrazing, and over exploitation of agriculture.

Because of the environmental significance of these plants and their declining numbers, genetic research on Haloxylon germplasm resources has garnered significant interest (Song \& Jia, 2000; Sheng et al., 2004, 2005; Zhang et al., 2006a, 2006b). However, Haloxylon plants possess only fine green assimilating shoots, without leaves, making the evaluation of their phenotypic diversity difficult. Further, the detection of genetic diversity within Haloxylon germplasm resources has been slowed by a lack of morphological markers (Sheng et al., 2004, 2005; Zhang et al., 2006a, 2006b; Wang et al., 2009; Suo et al., 2012a). A recent study by Long et al. (2014) used RNA-seq data to elucidate the Haloxylon transcriptome, providing a valuable sequence resource for further genetic and genomic studies; however, genetic information for members of the Haloxylon genus, and how they might differ from one another, is limited.

Each leaf cell of plants contains 1,000 to 10,000 chloroplasts (cp), which are key organelles for photosynthesis and other biochemical pathways such as the biosynthesis of starch, fatty acids, pigments, and amino acids (Dong et al., 2013b; Raman and Park, 2016). Since the first cp genome of Nicotiana tabacum was sequenced in 1986, around 800 complete cp genome sequences have been made available in the National Center for Biotechnology Information organelle genome database. These data are valuable sources of genetic markers for phylogenetic analyses, genetic diversity evaluation, and plant molecular identification (Dong et al., 2012, 2013a, 2013b, 2014; Ni et al., 2016; Suo et al., 2012b).

There are two published complete cp genome sequences (Spinacia oleracea and Beta vulgaris subsp. vulgaris) from members of the Amaranthaceae family (Li et al., 2014; Schmitz-Linneweber et al., 2001). 
83

However, the determination of the cp genome from Haloxylon plants is of further significance for potentially enhancing our understanding of their adaptability to severe desert environmental conditions, and their genomic evolution within the Amaranthaceae. Here, we report the complete cp genomes from two Haloxylon species, $H$. ammodendron and $H$. persicum, including patterns of nucleotide substitutions, microstructural mutation, and simple sequence repeats (SSRs). We further performed genomic comparative analyses on these and two other representative Amaranthaceae species, to better understand the evolutionary relationships within this family.

\section{MATERIALS \& METHODS}

\section{Sampling and DNA extraction}

Fresh young shoots of $H$. ammodendron (HA) and H. persicum (HP) were collected in May 2011 from Minqin Eremophytes Botanical Garden (N 38³4', E 10259', Altitude 1378 m), Gansu Province, China (under the leadership of Gansu Desert Control Research Institute, 390 Beibinhe West Road, Anning District, Lanzhou, Gansu 730070, China). These HA and HP plants were originally introduced from the Turpan Desert Botanical Garden of Chinese Academy of Sciences, Xinjiang Uygur Autonomous Region. The shoots from each accession were immediately dried using silica gel for future DNA extraction. Total genomic DNA (gDNA) was extracted from each using the Plant Genomic DNA Kit (DP305) from Tiangen Biotech (Beijing) Co., Ltd., China. The approval numbers are 2012BAD16B0101 and 80117B1001 for field permit of the research.

\section{Chloroplast genome sequencing}

The HA and HP cp genomes were sequenced using the short-range PCR method reported by Dong et al. (2012, 2013). The PCR protocol was as follows: preheating at $94^{\circ} \mathrm{C}$ for $4 \mathrm{~min}, 34$ cycles at $94^{\circ} \mathrm{C}$ for $45 \mathrm{~s}$, annealing at $55^{\circ} \mathrm{C}$ for $40 \mathrm{~s}$, and elongation at $72^{\circ} \mathrm{C}$ for $1.5 \mathrm{~min}$, followed by a final extension at $72^{\circ} \mathrm{C}$ for $10 \mathrm{~min}$. PCR amplification was performed in an Applied Biosystems VeritiTM 96-Well Thermal Cycler (Model\#: 9902, made in Singapore). The amplicons were sent to Shanghai Majorbio Bio-Pharm Technology Co., Ltd (Beijing) for Sanger sequencing in both the forward and reverse directions using a 3730xl DNA analyzer (Applied Biosystems, Foster City, CA, USA). DNA regions containing poly structures or that were difficult to amplify were further sequenced using newly designed primer pairs for confirming reliable and high quality sequencing results. 
112 Chloroplast genome assembling and annotation

113 The cp DNA sequences were manually confirmed and assembled using Sequencher (v4.6) software, and cp 114 genome annotation was performed using the Dual Organellar Genome Annotator (DOGMA) (Wyman et al., 115 2004). BLASTX and BLASTN searches were utilized to accurately annotate the protein-encoding genes and to 116 identify the locations of the transfer RNAs (tRNAs) and ribosomal RNAs (rRNAs). Gene annotation 117 information from other closely related plant species was also used for confirmation when the boundaries of the introns or exons could not be precisely determined because of the limited power of BLAST in cp genome annotation (e.g., for some short exons of 6-9 nt in length, such as in the case of rps 16, petB, and petD). Promoter, intron, and exon boundaries, as well as the location of stop codons for all protein-encoding genes,

121 have been identified accurately. The cp genome map was drawn using Genome Vx software (Conant \& Wolfe, 2008) (http://wolfe.ucd.ie/GenomeVx/), and the cp genome sequences have been deposited to GenBank with the following accession numbers: KF534478 for HA and KF534479 for HP (https://www.ncbi.nlm.nih.gov/nuccore/?term=Haloxylon+chloroplast+genome).

\section{Repeat structure analysis}

Gramene Simple Sequence Repeat Identification Tool software (

http://www.gramene.org/db/markers/ssrtool)(Benson, 1999) was utilized to search for simple sequence repeat loci in the cp genome sequences, with the threshold value of repeat number as $\geq 10$ for mono-nucleotide repeats, $\geq 5$ for di-nucleotide repeats, $\geq 4$ for tri-nucleotide repeats, and $\geq 3$ for tetra-nucleotide, penta-nucleotide, or hexa-nucleotide repeats.

\section{Gene content analysis and comparative genomics}

The mVISTA program was employed in Shuffle-LAGAN mode (Frazer et al., 2004) to compare the complete HA and HP cp genomes. These were aligned using MUSCLE software (Thompson et al., 1997) and were manually adjusted using Se-Al 2.0 (Rambaut, 1996). Variable sites in the cp genome were calculated using 
139

140

141

142

143

sequence matrix, the micro-structure events were checked manually and were further divided into three categories: (i) microsatellite-related insertions/deletions (indels), (ii) non-microsatellite-related indels, (iii) and inverted sequences. Using the HA cp genome sequence as the standard reference, the size, location, and evolutionary direction of the microstructure events were counted. The proposed secondary structures of the inverted regions in the cp genomes of HA and HP were analyzed using mfold software (Zuker, 2003). The complete cp genome sequences of S. oleracea (GenBank accession number AJ400848.1, Spinacia L.) (Schmitz-Linneweber et al., 2001) and B. vulgaris subsp. vulgaris (GenBank accession number KJ081864.1, Beta vulgaris subsp. vulgaris) (Li et al., 2014), two closely related species in the Amaranthaceae family, were downloaded from GenBank databases (www.ncbi.nlm.nih.gov). These were used for comparison with the complete cp genomes of HA and HP.

\section{RESULTS \& DISCUSSION}

\section{Genome features}

Similar to the typical cp genome structure in other higher plants, the Haloxylon cp genome is a doublestranded, circular DNA molecule of $151,570 \mathrm{bp}$ in length in HA and 151,586 bp in length in HP. It also includes a large single copy region (LSC) of 84,214 bp in HA and 84,217 bp in HP and a small single copy region (SSC) of 19,014 bp in HA and 19,015 bp in HP; these are separated by a pair of inverted repeats (IR) (24,171 bp in HA and 24,177 bp in HP) (Fig. 1). The GC content in this IR region is $43.0 \%$ in HA and $42.7 \%$ in $\mathrm{HP}$, and the GC content in the LSC and SSC regions is $34.4 \%$ (LSC) and $29.7 \%$ (SSC) in HA and $34.5 \%$ (LSC) and 29.7\% (SSC) in HP (Table 1).

Among the four Amaranthaceae species included in our analyses, which represent three genera, the longest cp genomes (151,570 bp for HA and 151,586 bp for HP) are 1935 bp to $1951 \mathrm{bp}$ larger than the shortest one (149,635 bp for B. vulgaris subsp. vulgaris) (Li et al., 2014). The size of the $S$. oleracea cp genome (150,725 bp) (Schmitz-Linneweber et al., 2001) is intermediate (Table 1). Notably, the cp genomes of HP and HA are quite similar in size; the HP cp is only 16 bp longer than that of HA, with minor differences between them.

There are a total of 112 genes in the Haloxylon cp genome, including 78 coding genes, 18 of which are duplicated genes in the IR region, 30 tRNA genes, and four ribosomal RNA genes (16S, 23S, 5S, 4.5S) (Fig. 1, Table S1). Based on their predicted functions, these genes can be divided into three categories, 1) genes related 
167 to transcription and translation; 2) genes related to photosynthesis; 3) genes related to the biosynthesis of 168 amino acids, fatty acids, etc., and some functionally unknown genes (Table S1). The S. oleracea cp also 169 contains the same 78 protein-coding genes, whereas the cp in B. vulgaris has 79 . This species contains an additional gene (rpl23), which is a pseudogene in the other species (Fig.1, Table S1). There are 17 genes harboring introns in the cp genomes of the four Amaranthaceae species analyzed (one class I intron, trnLUUA, and 16 class II introns), and two of these genes, $y c f 3$ and $c l p P$, contain two introns each (Table 2).

Several angiosperm lineages have lost introns from the rpl2 gene independently (Downie et al., 1991), which could also be regarded as a characteristic feature of the core members of the Caryophyllales (Logacheva et al., 2008). In each of the four Amaranthaceae cp genomes in our analysis, the rpl2 gene has lost its intron. Some authors have proposed that intron loss is not always a dependable marker of phylogenetic relationships (Millen et al., 2001; Dong et al., 2013b; Raman \& Park, 2016), and further study, including the sampling of more taxa, is needed to clarify this issue.

\section{Expansion and contraction of the border regions in Haloxylon cp genomes}

To analyze these Amaranthaceae species at the genome-level, the sequences of all the four cp genomes were plotted using the VISTA program (Frazer et al., 2004), using the annotation of HA as a reference (Fig. 2). Similar to other angiosperms, we observed that the IR region is more conserved in these species than the LSC and SSC regions.

The expansion and contraction of the border regions between the two IR regions and the single copy region have contributed to genome size variations among plant lineages (Dong et al., 2013b; Goremykin et al., 2003; Ni et al., 2016). Therefore, we next compared the exact IR border positions and their adjacent genes among the four Amaranthaceae cp genomes (Fig. 3). From these data, we see that the IRa/LSC border is generally located upstream of the $\operatorname{trn} \mathrm{H}^{\mathrm{GUG}}$ gene. The distance between the IRa/LSC border and the $\operatorname{trn} \mathrm{H}^{\mathrm{GUG}}$ gene is $1 \mathrm{bp}$ in the Haloxylon cp genomes and 2 bp in Beta genus, with no separation in Spinacia (Fig. 3). The IR region is expanded by $763 \mathrm{bp}$ and enters the 5' end of the ycfl gene in Haloxylon species, whereas it is expanded by $1427 \mathrm{bp}$ and $1492 \mathrm{bp}$, respectively, in Spinacia and Beta. Except for the expansion of the $y c f 1$ gene, the IR region extends to the rps19 gene in all of four Amaranthaceae cp genomes. The rps19 pseudogene was not 
195

196

197

198

199

200

201

202

203

204

205

206

207

208

209

210

211

212

213

214

215

216

217

218

219

220

221

222

investigated species of the Amaranthaceae, they contribute little to the overall size differences in the $\mathrm{cp}$ genomes. The exon at the 5' end of the rps 12 gene is located in the LSC region, and the intron and 3'-end exon of the gene are situated in the IR region in all four Amaranthaceae species.

\section{Indels and SNPs}

Indel and single nucleotide polymorphism (SNP) sites are important molecular features valuable for development of DNA markers that are useful for plant identification and genetic analysis of population structure. (Dong et al., 2012, 2013a, 2013b, 2014; Suo et al. 2012b, 2015, 2016). We detected 23 indels in the cp genome sequence alignment of HA and HP, including 16 indels caused by microsatellite repeat variations and seven non-microsatellite-related indels (Table 3). Most of the indel events occurred in non-coding regions (21/23). A large portion of the indels related to microsatellite repeat variations are characterized by a single base mutation; six insertions of this type were observed in the HA cp genome. The non-microsatellite-related indels were found to contain mostly five to six variable base sites, and two insertions of this type were detected in the HA cp genome.

Forty-four SNPs were detected in the HA and HP cp genomes (Table 4), which is considerably less than what was found between the cp genomes of other closely related plant species, including Oryza sativa and Oryza nivara (159 SNPs, Masood et al., 2004), Machilus yunnanensis and Machilus balansae (231 SNPs, Song et al., 2015), Citrus sinensis and Citrus aurantiifolia (330 SNPs, Su et al., 2014), Panax ginseng and Palax notoginseng (464 SNPs, Dong et al., 2014), and Solanum tuberosum and Solanum bulbocastanum (591 SNPs, Chung et al., 2006). Of note, the indel and SNP mutation events in the Haloxylon cp genomes were not randomly distributed, but rather, clustered as "hotspots" (Shaw et al., 2007; Worberg et al., 2007). It is likely that such mutational dynamics created the highly variable regions in the genome (Suo et al., 2012b; Song et al., 2015).

\section{Patterns of nucleotide substitutions}

Overall, the differences between the HA and HP cp genomes are minor, with a genetic distance of 0.00029 between them (Table 4). In total, 44 variable nucleotide sites were detected, 23 of which were found in intergenic regions, six in introns, and 15 in protein-encoding regions. 
223

224

225

226

227

228

229

230

231

232

233

234

235

236

237

238

239

240

241

242

243

244

245

246

247

248

249

250

We also found that the probability of occurrence for the various nucleotide substitutions is different, depending on the mutation, as shown in Fig. 4. The most frequently occurring mutations are from $\mathrm{A}$ to $\mathrm{C}$ and from $\mathrm{T}$ to $\mathrm{G}$ (12 times each); mutations from $\mathrm{A}$ to $\mathrm{T}$ and from $\mathrm{T}$ to $\mathrm{A}$ exhibited the lowest frequency (only one occurrence of each). The ratio of transitions (Ts) and transversions (Tv) was 0.76 in the cp genome of Haloxylon species.

In the gene-encoding regions of the HA and HP cp genomes, a total of 15 variable base sites were detected in 11 protein-encoding genes. Specifically, we found one mutation in each of the following genes: atpA, atpI, $m a t \mathrm{~K}, n d h \mathrm{~F}, n d h \mathrm{I}, p s b \mathrm{C}, r p o \mathrm{~B}, r p s 15$, and $r p s 3$. Two genes, $r p o \mathrm{C} 2$ and $y c f 1$, each contained three mutation sites (Table 5). These mutations included six Ts and nine Tv. Ten nonsynonymous substitutions occurred simultaneously in seven genes (Table 5).

\section{Repeat structure feature}

Simple sequence repeats (SSRs) are also called microsatellites. Within the cp genomes of HA and HP, 59 different SSR loci were detected. Of these, 44 loci are mono-nucleotide repeats, three are di-nucleotide repeats, one is a tri-nucleotide repeat, and 11 are tetra-nucleotide repeats; penta-nucleotide repeats or those containing a higher number of nucleotide repeats were not detected. Among the SSR loci detected, the most frequently observed repeats were A/T and AT/TA, accounting for $77.97 \%$ of the total number of SSR loci (Table 6). By comparison, in the cp genomes of M. yunnanensis and M. balansae, 36 SSR loci were identified (Song et al., 2015).

\section{Inversions}

Inversions are important events in the evolution of plant cp genomes. Smaller inversions are less frequent in these genomes, and they are generally associated with hairpins (Fig. 5). Most inversions are found in spacers and introns, and in most cases, the presence/absence of inversions is highly homoplastic during cp genome evolution (Kim \& Lee, 2005; Catalano et al., 2009), even at the population level (Quandt \& Stech, 2004). A sequence alignment of the Haloxylon cp genomes revealed that an inversion event of $14 \mathrm{bp}$ and one of $3 \mathrm{bp}$ occur in the petA-psbJ intergenic region and in the rpl16 intron, respectively. The two inverted sequences are predicted to form secondary hairpin structures, with repeat sequences of $27 \mathrm{bp}$ and $19 \mathrm{bp}$ at the two ends, 
251

252

253

254

255

256

257

258

259

260

261

262

263

264

265

266

267

268

269

270

271

272

273

274

275

276

277

respectively (Fig. 5).

\section{Pseudogenes}

Pseudogenes have been defined as nonfunctional regions of genomic DNA that originally derived from functional genes (Balakirev \& Ayala, 2003). These are evolutionary relics of functional components in the genome that provide important information regarding the history of the gene and genome evolution (Balakirev \& Ayala, 2003; Zou et al., 2009; Choi \& Park, 2015). The rpl22 and rps18 genes are putative pseudogenes in the Paeoniaceae (Dong et al., 2013b), whereas the atp B gene is a pseudogene in Aster spathulifolius. Conversely, the $r p l 22, r p s 18$, and $a t p \mathrm{~B}$ genes are predicted to be normal and functional in the Haloxylon species, whereas rpl23 is a present as a pseudogene in the Haloxylon cp genomes (Fig. 1 and Table S1).

\section{CONCLUSIONS}

Two Haloxylon cp genomes were sequenced and characterized for the first time, and we found that they share the same overall organization and gene content found in most angiosperm cp genomes, including that of the closely related Spinacia and Beta species. The location and distribution of repeat sequences and differing nucleotide mutation sites between the two cp genomes were identified. The LSC/IRB/SSC/IRA boundary regions of the Amaranthaceae cp genomes were compared, and lightly intense variations were identified within the genus Haloxylon. The complete Haloxylon cp genome sequences reported here enhance the genomic information available for the Amaranthaceae family and further contribute to the study of germplasm diversity. These data represent a valuable source of markers for future research on Haloxylon population genetics.

\section{ACKNOWLEDGEMENTS}

The authors thank Prof. Borong Pan for advice and helpful discussion.

\section{REFERENCES}

Akhani H., Edwards G., Roalson E.H. 2007. Diversification of the old world Salsoleae s.l. (Chenopodiaceae): molecular phylogenetic analysis of nuclear and chloroplast data sets and a revised 
278

279

280

281

282

283

284

285

286

287

288

289

290

291

292

293

294

295

296

297

298

299

300

301

302

303

304

305

classification. International J Plant Sci 168: 931-956

APG III. 2009. An update of the Angiosperm Phylogeny Group classification for the orders and families of flowering plants: APG III. Botanical J Linnean Society 161: 105-121

Balakirev E.S., Ayala F.J. 2003. Psuedogenes: are they "junk" or functional DNA? Annual Rev Genet 37: $123-151$

Benson G. 1999. Tandem repeats finder: a program to analyze DNA sequences. Nucleic Acid Research 27(2): $573-580$

Catalano S.A., Saidman B.O., Vilardi J.C. 2009. Evolution of small inversions in chloroplast genome: a case study from a recurrent inversion in angiosperms. Cladistics 25, 93-104

Choi K.S., Park S.J. 2015. The complete chloroplast genome sequence of Aster spathulifolius (Asteraceae): genomic features and relationship with Asteraceae. Gene 572: 214-221

Chung H.J., Jung J.D., Park H.W., Kim J.H., Cha H.W., Min S.R., Jeong W.J., Liu J.R. 2006. The complete chloroplast genome sequences of Solanum tuberosum and comparative analysis with Solanaceae species identified the presence of a 241-bp deletion in cultivated potato chloroplast DNA sequence. Plant Cell Rep 25: 1369-1379 DOI:10.1007/s00299-006-0196-4.

Conant G.C., Wolfe K.H. 2008. GenomeVx: simple web-based creation of editable circular chromosome maps. Bioinformatics 24(6): 861-862.

Cosner M.E., Jansen R.K., Palmer J.D., Downie S.R. 1997. The highly rearranged chloroplast genome of Trachelium caeruleum (Campanulaceae): multiple inversions, inverted repeat expansion and contraction, transposition, insertions/deletions, and several repeat families. Curr Genet 31: 419-429 DOI: $10.1007 / \mathrm{s} 002940050225$

Dong W.P., Liu H., Xu C., Zuo Y.J., Chen Z.J., Zhou S.L. 2014. A chloroplast genomic strategy for designing taxon specific DNA mini-barcodes: a case study on ginsengs. BMC Genetics 15:138

Dong W.P., Xu C., Cheng T., Lin K., Zhou S.L. 2013a. Sequencing angiosperm plastid genomes made easy: a complete set of universal primers and a case study on the phylogeny of Saxifragales. Genome Biol Evol 5(5): 989-997

Dong W.P., Xu C., Cheng T., Zhou S.L. 2013b. Complete chloroplast genome of Sedum sarmentosum and chloroplast genome evolution in Saxifragales. PLOS ONE 8(10): e77965 DOI:10.1371/journal. 
306

307

308

309

310

311

312

313

314

315

316

317

318

319

320

321

322

323

324

325

326

327

328

329

330

331

332

333

pone.0077965.

Dong W.P., Liu J., Yu J., Wang L., Zhou S.L. 2012. Highly variable chloroplast markers for evaluating plant phylogeny at low taxonomic levels and for DNA barcoding. PLoS ONE 7(4): e35071 DOI:10.1371/ journal.pone.0035071.

Doyle J.J., Doyle J.L., Palmer J.D. 1995. Multiple independent losses of two genes and one intron from legume chloroplast genomes. Syst Bot 20: 272-294 DOI:10.2307/2419496.

Downie S.R., Olmstead R.G., Zurawski G., Soltis D.E., Soltis P.S., Watson J.C., Palme J.D. 1991. Six independent losses of the chloroplast DNA $r p l 2$ intron in dicotyledons: molecular and phylogenetic implications. Evolution 45: 1245-1259 DOI:10. 2307/2409731.

Downie S.R., Palmer J.D. 1992. Use of chloroplast DNA rearrangements in reconstructing plant phylogeny. In Soltis P.S., D.E. Soltis, J.J. Doyle (eds) Molecular Systematics of Plants. Chapman and Hall, New York, London, pp14-35

Goremykin V.V., Hirsch-Ernst K.I., Wolfl S., Hellwig F.H. 2003. Analysis of the Amborella trichopoda chloroplast genome sequence suggests that Amborella is not a basal angiosperm. Mol Biol Evol 20: 14991505 DOI: $10.1093 / \mathrm{molbev} / \mathrm{msg} 159$.

Frazer K.A., Pachter L., Poliakov A., Rubin E.M., Dubchak I. 2004. VISTA: computational tools for comparative genomics. Nucleic Acids Res 32: W273-W279 DOI:10.1093/nar/gkh053. PubMed: 15215394.

Jansen R.K., Kaittanis C., Saski C., Lee S.B., Tomkins J., Alverson A.J., Daniell H. 2006. Phylogenetic analyses of Vitis (Vitaceae) based on complete chloroplast genome sequences: effects of taxon sampling and phylogenetic methods on resolving relationships among rosids. BMC Evol Biol 6: 32 DOI:10.1186/14712148-6-32.

Jia Z.Q., Lu Q. 2004. Haloxylon Bunge. China Environmental Science Press, Beijing, China (in Chinese).

Kim K.J., Lee H.L. 2005. Wide spread occurrence of small inversions in the chloroplast genomes of land plants. Molecules and Cells 19:104-113

Li H., Cao H., Cai Y.F., Wang J.H., Qu S.P., Huang X.Q. 2014. The complete chloroplast genome sequence of sugar beet (Beta vulgaris ssp. vulgaris). Mitochondrial DNA 25: 209-211

Librado P., Rozas J. 2009. DnaSP v5: a software for comprehensive analysis of DNA polymorphism data. Bioinformatics 25: 1451-1452 
334

335

336

337

338

339

340

341

342

343

344

345

346

Logacheva M.D., Samigullin T.H., Dhingra A., Penin A.A. 2008. Comparative chloroplast genomics and phylogenetics of Fagopyrum esculentum ssp. ancestrale -a wild ancestor of cultivated buckwheat. BMC Plant Biology 8: 59 DOI:10.1186/1471-2229-8-59 PMID: 18492277.

Long Y., Zhang J., Tian X., Wu S.S., Zhang Q., Zhang J.P., Dang Z.H., Pei X.W. 2014. De novo assembly of the desert tree Haloxylon ammodendron (C. A. Mey.) based on RNA-Seq data provides insight into drought response, gene discovery and marker identification. BMC Genomics 15: 1111. DOI:10.1186/14712164-15-1111.

Masood M.S., Nishikawa T., Fukuoka S., Njenga P.K., Tsudzuki T., Kadowaki K. 2004. The complete nucleotide sequence of wild rice (Oryza nivara) chloroplast genome: first genome wide comparative sequence analysis of wild and cultivated rice. Gene 340: 133-139 DOI:10.1016/j.gene. 2004.06.008.

Millen R.S., Olmstead R.G., Adams K.L., Palmer J.D., Lao N.T., Heggie L., Kavanaghd T.A., Hibberde J.M., Graye J.C., Mordenf C.W., Calieg P.J., Jermiinh L.S., Wolfe K.H. 2001. Many parallel losses of infA from chloroplast DNA during angiosperm evolution with multiple independent transfers to the nucleus. Plant Cell 13: 645-658 DOI:10.1105/tpc.13.3.645.

Ni L.H., Zhao Z.L., Xua H.X., Chen S.L., Dorje G. 2016. The complete chloroplast genome of Gentiana straminea (Gentianaceae), an endemic species to the Sino-Himalayan subregion. Gene 577: 281-288

Pyankov V.I., Artyusheva E.G., Edwards G.E., Black C.C. JR, Soltis P.S. 2001. Phylogenetic analysis of tribe Salsoleae (Chenopodiaceae) based on ribosomal ITS sequences: implications for the evolution of photosynthesis types. Am J Bot 88(7): 1189-1198

Quandt D., Stech M. 2004. Molecular evolution and phylogenetic utility of the chloroplast $\operatorname{trnT}$-trnF region in bryophytes. Plant Biol 6: 545-554

Raman G., Park S. 2016. The complete chloroplast genome sequence of Ampelopsis: gene organization, comparative analysis, and phylogenetic relationships to other angiosperms. Front Plant Sci 7: 341 DOI: 10.3389/fpls.2016.00341.

Rambaut A. 1996. Se-Al: sequence alignment editor. version 2.0. Oxford: University of Oxford, Department of Zoology

Schmitz-Linneweber C., Maier R.M., Alcaraz J.P., Cottet A., Herrmann R.G., Mache R. 2001. The plastid chromosome of spinach (Spinacia oleracea): complete nucleotide sequence and gene organization. 
362

363

364

365

366

367

368

369

370

371

372

373

374

375

376

377

378

379

380

381

382

383

384

385

386

387

388

389

Plant Mol Biol 45: 307-315 DOI:10.1023/A:1006478403810. PubMed: 11292076.

Shaw J., Lickey E.B., Schilling E.E., Small R.L. 2007. Comparison of whole chloroplast genome sequences to choose non-coding regions for phylogenetic studies in angiosperms: the tortoise and the hare III. Am J Bot 94: 275-288 DOI:10.3732/ajb.94.3.275.

Sheng Y., Zheng W.H., Quan P.K., Ma K.P. 2004. Population genetic structure of a dominant desert tree, Haloxylon ammodendron (Chenopodiaceae), in the southeast Gurbantunggut desert detected by RAPD and ISSR markers. Acta Botanica Sinica 46: 675-681 (in Chinese with English Abstract)

Sheng Y., Zheng W.H., Quan P.K., Ma K.P. 2005. Genetic variation within and among populations of a dominant desert tree Haloxylon ammodendron (Amaranthaceae) in China. Ann Bot London 96: $245-252$.

Song C.S., Jia K.F. 2000. Scientific survey of Wulate Haloxylon ammodendron forest nature reserve (The series of nature reserve). China Forestry Publishing House, Beijing, China (in Chinese with English Overview)

Song Y., Dong W., Liu B., Xu C., Yao X., Gao J., Corlett R.T. 2015. Comparative analysis of complete chloroplast genome sequences of two tropical trees Machilus yunnanensis and Machilus balansae in the family Lauraceae. Front. Plant Sci. 6: 662 DOI:10.3389/fpls.2015.00662.

Su H.J., Hogenhout S.A., Al-Sadi A.M., Kuo C.H. 2014. Complete chloroplast genome sequence of omani lime (Citrus aurantiifolia) and comparative analysis within the Rosids. PLoS ONE 9: e113049 DOI: 10.1371/journal.pone.0113049.

Suo Z.L., Jia Z.Q., Lu Q., Pan B.R., Jin X.B., Xu G., Peng X.Q., Sun H.B., Tao Y.H. 2012a.

Distinguishing Haloxylon persicum and H. ammodendron (Haloxylon Bunge, Amaranthaceae) using DNA Marker. AASRI Procedia 1: 305-310

Suo Z.L., Zhang C.H., Zheng Y.Q., He L.X., Jin X.B., Hou B.X., Li J.J. 2012b. Revealing genetic diversity of tree peonies at micro-evolution level with hyper-variable chloroplast markers and floral traits. Plant Cell Reports 31: 2199-2213

Suo Z.L., Chen L.N., Pei D., Jin X.B., Zhang H.J. 2015. A new nuclear DNA marker from ubiquitin ligase gene region for genetic diversity detection of walnut germplasm resources. Biotechnology Reports 5: 40-45

Suo Z.L., Li W.Y., Jin X.B., Zhang H.J. 2016. A new nuclear DNA marker revealing both microsatellite 
390

variations and single nucleotide polymorphic loci: a case study on classification of cultivars in Lagerstroemia indica L. J Microb Biochem Technol 8: 266-271 DOI:10.4172/1948-5948.1000296.

Tamura K., Stecher G., Peterson D., Filipski A., Kumar S. 2013. MEGA6: molecular evolutionary genetics analysis version 6.0. Mol Biol Evol 30: 2725-2729. DOI:http://dx.doi.org/10.1093/molbev/mst197.

Thompson J.D., Gibson T.J., Plewniak F., Jeanmougin F., Higgins D.G. 1997. The CLUSTAL_X windows interface: flexible strategies for multiple sequence alignment aided by quality analysis tools. Nucleic Acids Res 25: 4876-4882 DOI:10.1093/nar/25.24.4876. PubMed: 9396791.

Wang X.M., Yang D.Y., Tian Y.Z., Zhang B.W., Tu P.F., Sun Q.S., Li X.B. 2009. Inter-simple sequence repeats analysis of Haloxylon ammodendron from seeds carried back by "Shenzhou No.4" spaceship. J Northwest University 39: 259-263 (in Chinese with English Abstract)

Worberg A., Quandt D., Barniske A.M., Lohne C., Hilu K.W., BorschT. 2007. Phylogeny of basal eudicots: insights from non-coding and rapidly evolving DNA. Organ Diver Evol 7: 55-77 DOI:10.1016/ j.ode.2006.08.001.

Wyman S.K., Jansen R.K., Boore J.L. 2004. Automatic annotation of organellar genomes with DOGMA. Bioinformatics 20: 3252-3255 DOI: 10.1093/bioinformatics/bth352. PubMed: 15180927.

Zhang P., Dong Y.Z., Wei Y., Hu C.Z. 2006a. ISSR analysis of genetic diversity of Haloxylon ammodendron (C. A. Mey.) Bunge in Xinjiang. Acta Botanica Boreali-Occidentalia Sinica 26: 1337-1341 (in Chinese with English Abstract)

Zhang P., Dong Y.Z., Wei Y., Hu C.Z. 2006b. Analysis of genetic diversity of Haloxylon persicum (Chenopodiaceae) in Xinjiang by ISSR. Acta Bot Yunnaica 28: 359-362 (in Chinese with English Abstract)

Zhu G.L., Mosyakin S.L., Clemants S.E. 2004. Haloxylon Bunge (Chenopodiaceae). In Flora of China Editorial Committee (eds) Flora of China. Sci. Press, Beijing/Missouri Botanic Garden Press, St. Louis. 5: 395-396

Zou S.H., Lehti-Shiu M.D., Thibaud-Nissen F., Prakash T., Buell C.R., Shiu S.H. 2009. Evolutionary and expression signatures of pseudogenes in Arabidopsis and rice. Plant Physiol 151: 3-15

Zuker M. 2003. Mfold web server for nucleic acid folding and hybridization prediction. Nucleic Acids Research 31: 3406-3415 


\section{Table and Figure Legends}

420 Figure 1 Representative map of the two Haloxylon chloroplast genomes. Genome annotation was

421 performed using DOGMA. Genes drawn outside of the circle are transcribed clockwise, whereas those

422 represented inside the circle are transcribed counterclockwise. Small single copy (SSC), large single copy

423 (LSC), and inverted repeat (IRa, IRb) regions are indicated.

424 Figure 2 Identity plot comparing the chloroplast genomes of four Amaranthaceae species using

Haloxylon ammodendron as a reference sequence. The vertical scale indicates the percent identity, ranging from 50\%-100\%. The horizontal axis indicates the coordinates within the chloroplast genome. Genomic regions are color coded as protein-coding, rRNA, tRNA, intron, and conserved non-coding sequences (CNS).

Abbreviations HP: H. persicum; SO: Spinacia oleracea; BV: Beta vulgaris subsp. vulgaris.

Figure 3 Comparison of the junction positions between the single copy and IR regions among four Amaranthaceae genomes.

Figure 4 The nucleotide substitution patterns in the two Haloxylon chloroplast genomes. The patterns were divided into six types, as indicated by the six non-strand-specific base-substitution types (i.e., numbers of $\mathrm{G}$ to $\mathrm{A}$ and $\mathrm{C}$ to $\mathrm{T}$ sites for each respective set of associated mutation types). The $H$. ammodendron chloroplast genome was used as a standard.

Figure 5 The hairpin loops predicted to be formed by inversions in the Haloxylon chloroplast genomes.

Table 1 Summary of complete chloroplast genome features in Haloxylon.

Table 2 Genes with introns in Haloxylon ammodendron and $\boldsymbol{H}$. persicum and length of exons and introns.

Table 3 Indel mutation events in the chloroplast genomes of Haloxylon ammodendron and H.persicum.

Table 4 The nucleotide substitution patterns present in the two Haloxylon chloroplast genomes. ammodendron and $H$. persicum. 


\section{Supplemental Information}

447 Table S1 Genes found in the Haloxylon chloroplast genomes. 
Figure 1 (on next page)

Representative map of the two Haloxylon chloroplast genomes.

Genome annotation was performed using DOGMA. Genes drawn outside of the circle are transcribed clockwise, whereas those represented inside the circle are transcribed counterclockwise. Small single copy (SSC), large single copy (LSC), and inverted repeat (IRa, $\mathrm{IRb})$ regions are indicated. 


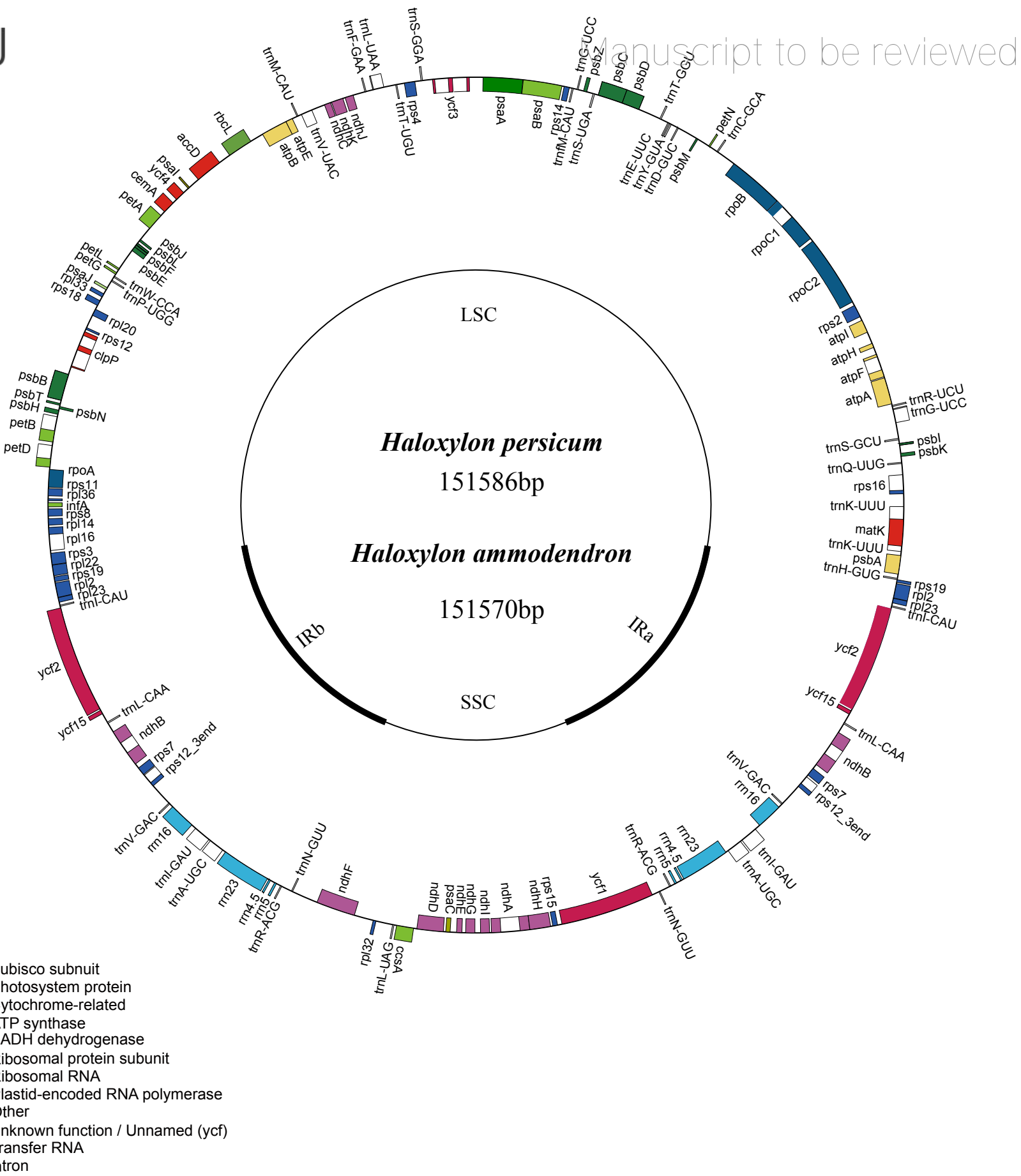




\section{Figure 2 (on next page)}

Identity plot comparing the chloroplast genomes of four Amaranthaceae species using Haloxylon ammodendron as a reference sequence.

The vertical scale indicates the percent identity, ranging from $50 \%-100 \%$. The horizontal axis indicates the coordinates within the chloroplast genome. Genomic regions are color coded as protein-coding, rRNA, tRNA, intron, and conserved non-coding sequences (CNS). Abbreviations HP: H. persicum; SO: Spinacia oleracea; BV: Beta vulgaris subsp. vulgaris. 
HA

BV

trnH trnK

trnKrps16 psbKtrnStrnG atpA atpF

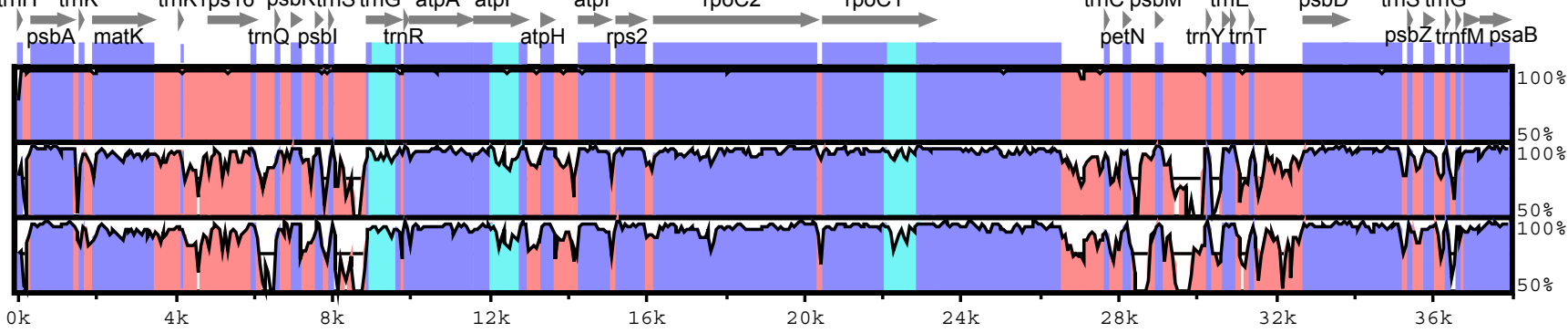

SO
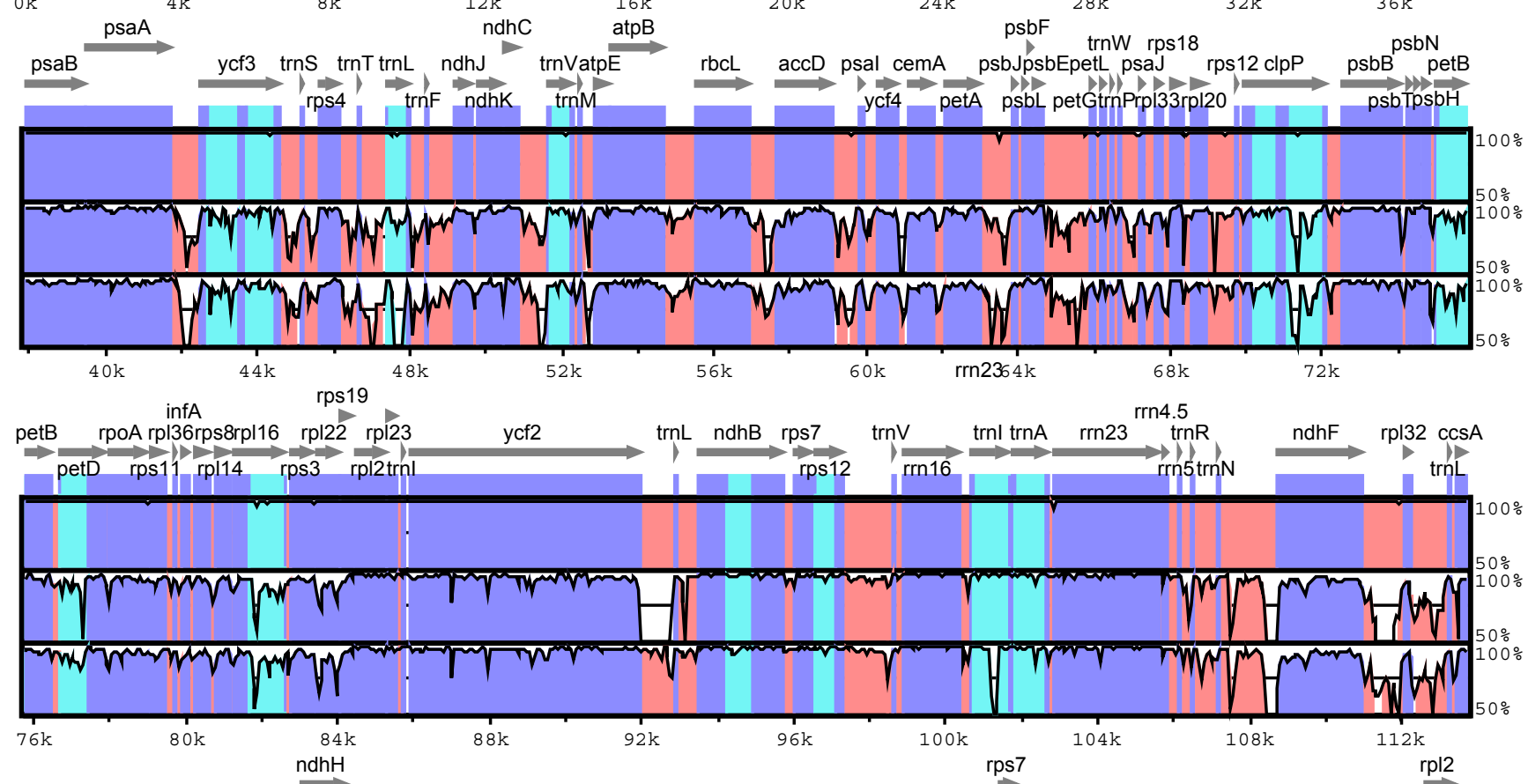

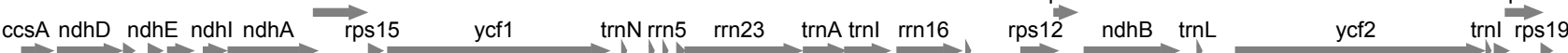

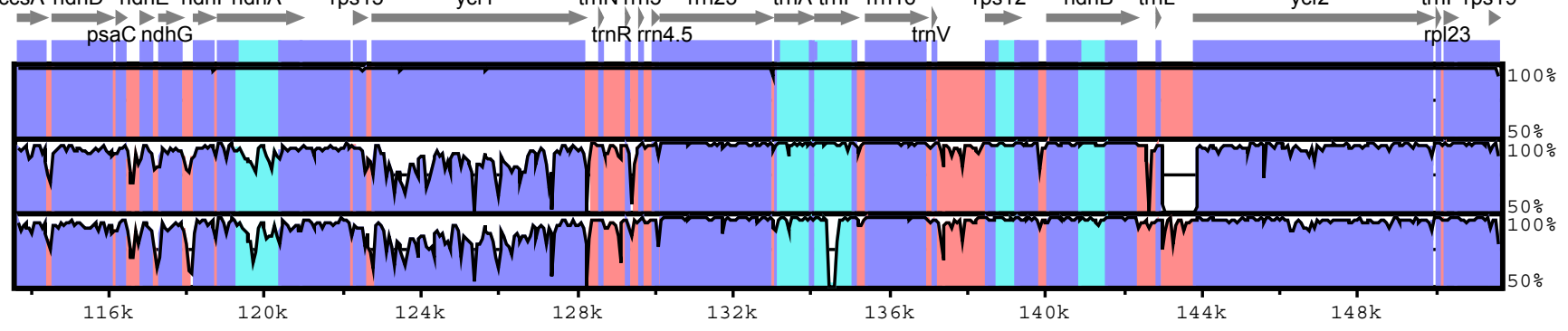




\section{Figure 3 (on next page)}

Comparison of the junction positions between the single copy and IR regions among four Amaranthaceae genomes. 


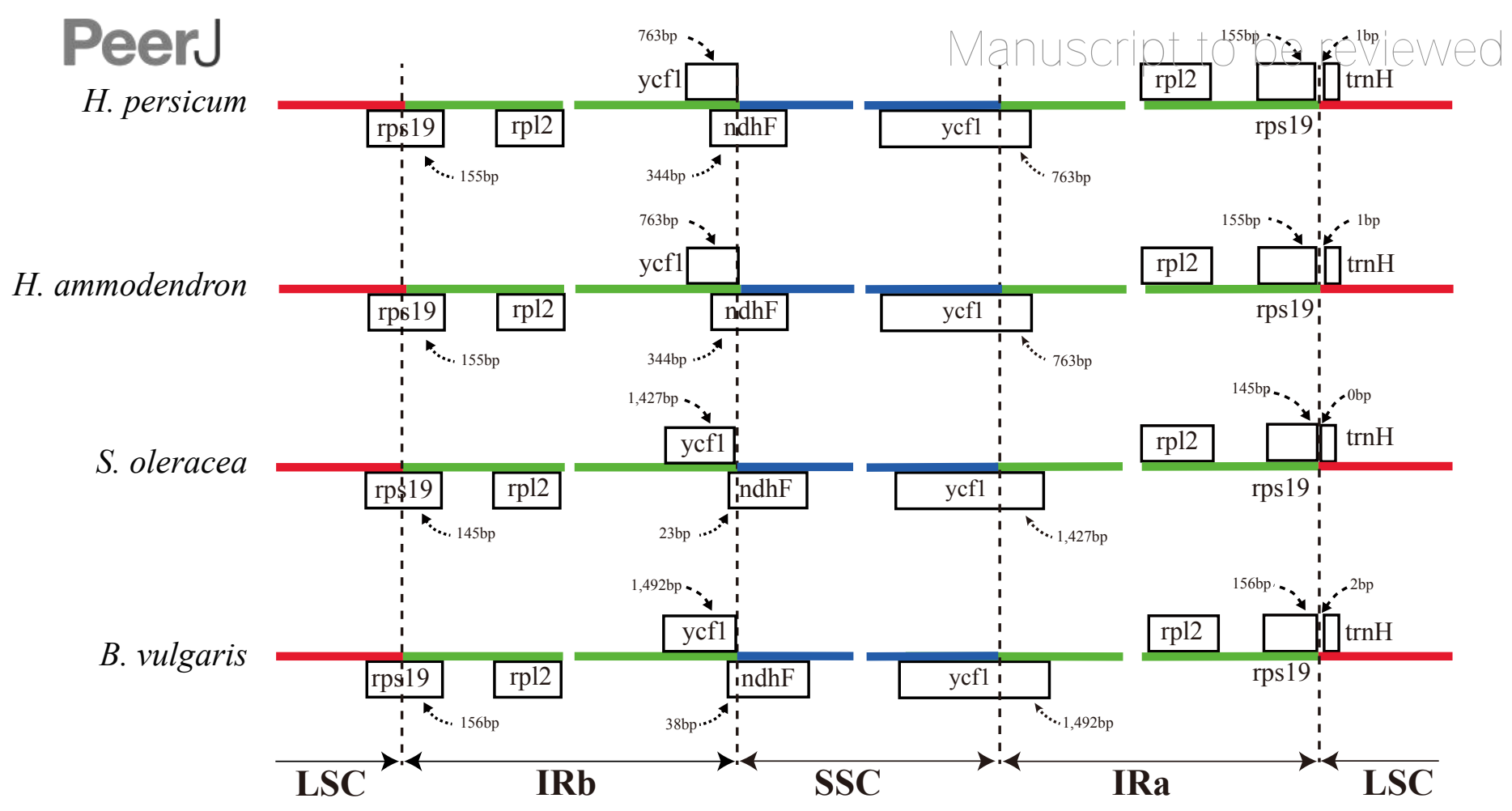




\section{Figure 4 (on next page)}

The nucleotide substitution patterns in the two Haloxylon chloroplast genomes.

The patterns were divided into six types, as indicated by the six non-strand-specific basesubstitution types (i.e., numbers of $\mathrm{G}$ to $\mathrm{A}$ and $\mathrm{C}$ to $\mathrm{T}$ sites for each respective set of associated mutation types). The $H$. ammodendron chloroplast genome was used as a standard. 


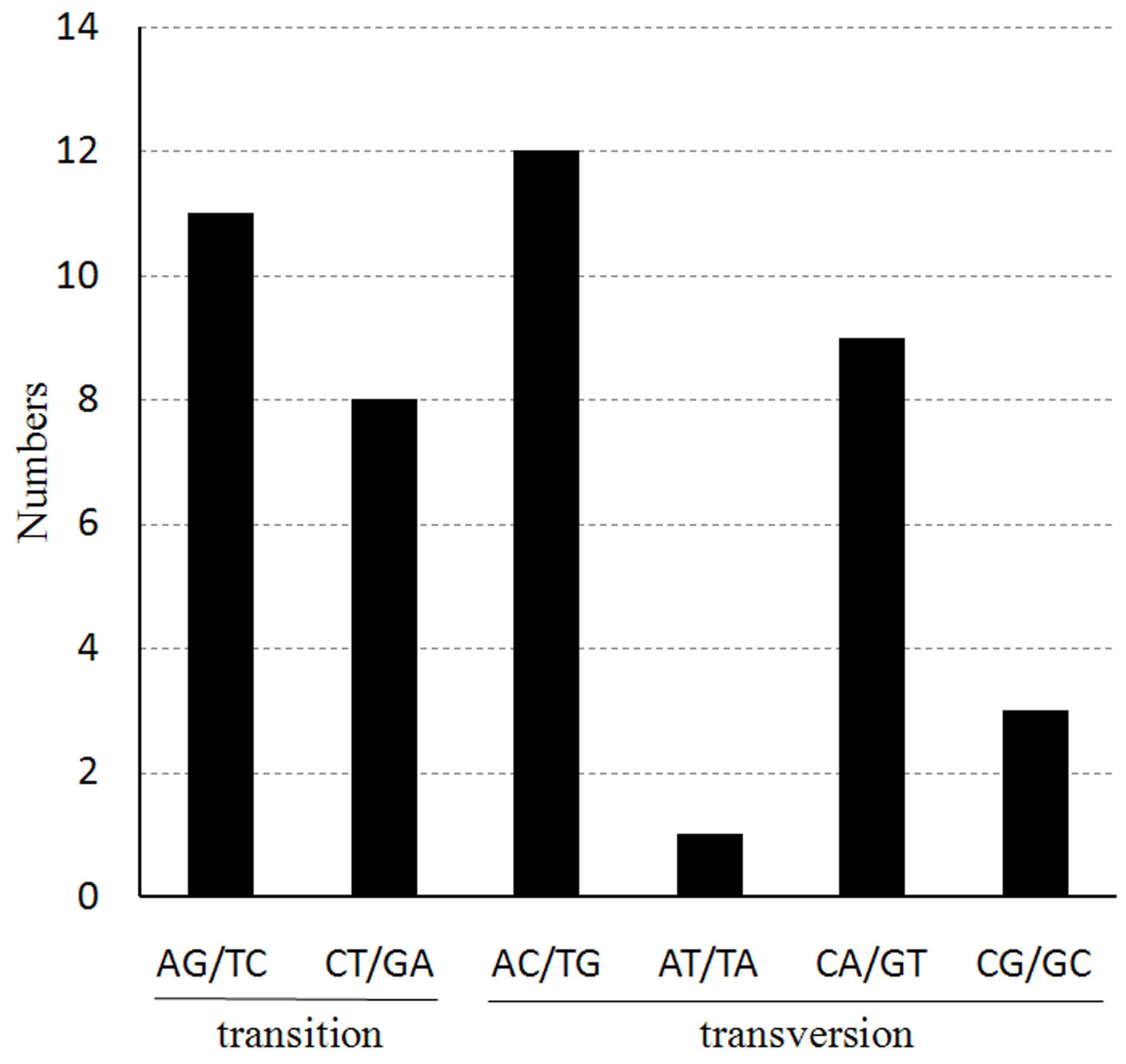




\section{Figure $\mathbf{5}$ (on next page)}

The hairpin loops predicted to be formed by inversions in the Haloxylon chloroplast genomes. 


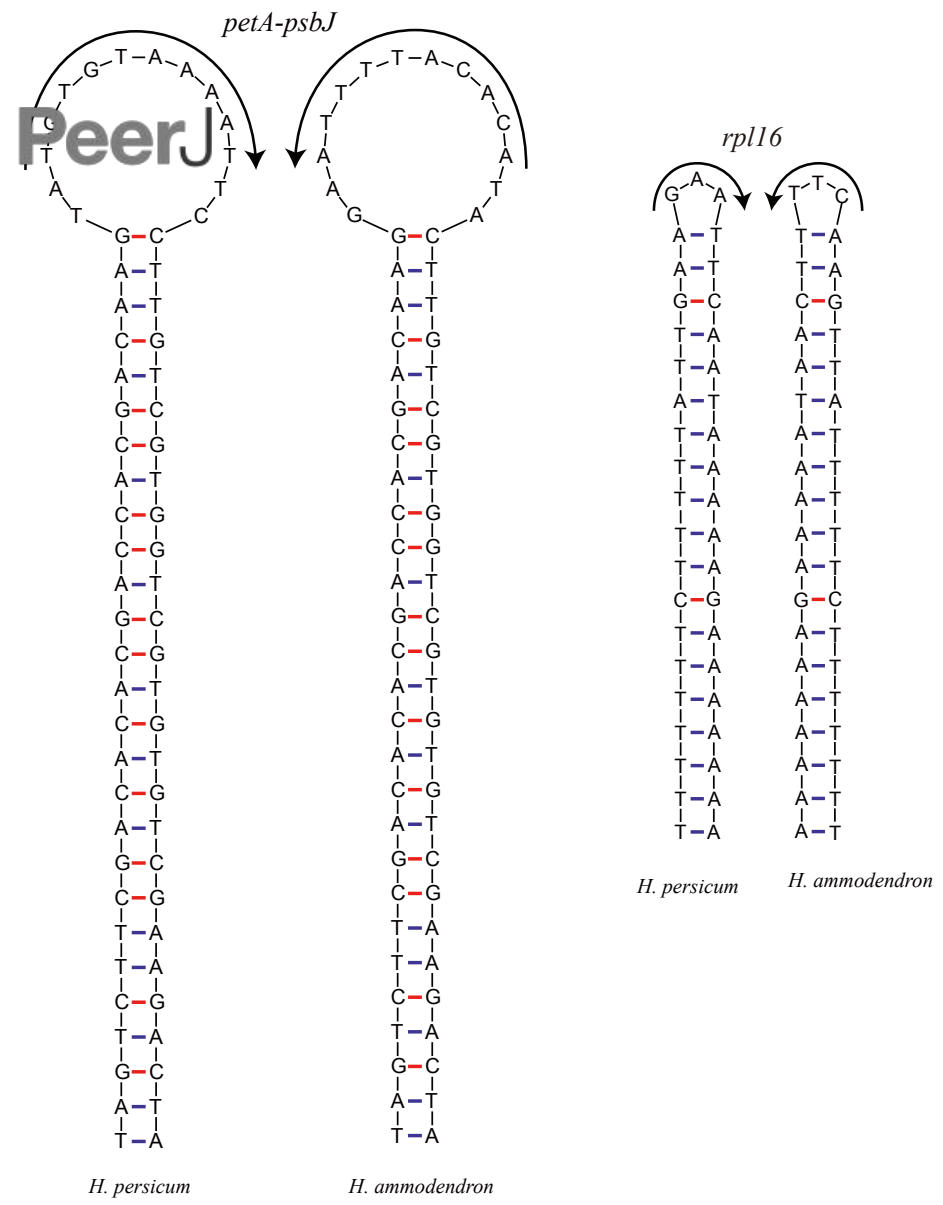




\section{Table 1 (on next page)}

Summary of complete chloroplast genome features in Haloxylon. 
Table 1 Summary of complete chloroplast genome features in Haloxylon.

\begin{tabular}{cllll}
\hline & H. ammodendron & H. persicum & Spinacia oleracea & Beta vulgaris \\
\hline Total cpDNA size & 151,570 & 151,586 & 150,725 & 149,635 \\
Length of LSC region & 84,214 & 84,217 & 82,719 & 83,057 \\
Length of IR region & 24,171 & 24,177 & 25,073 & 24,439 \\
Length of SSC region & 19,014 & 19,015 & 17,860 & 17,701 \\
Total GC content (\%) & 36.6 & 36.6 & 36.9 & 36.4 \\
LSC & 34.4 & 34.5 & 34.8 & 34.1 \\
IR & 43.0 & 43.0 & 42.7 & 42.2 \\
SSC & 29.7 & 29.7 & 29.8 & 29.2 \\
Total number of genes & 112 & 112 & 112 & 113 \\
protein encoding & 78 & 78 & 78 & 79 \\
tRNA & 30 & 30 & 30 & 30 \\
rRNA & 4 & 4 & 4 & 4 \\
Pseudogenes & 2 & 2 & 2 & 1 \\
\hline
\end{tabular}

3 


\section{Table 2(on next page)}

Genes with introns in Haloxylon ammodendron and $H$. persicum and length of exons and introns. 
Table 2 Genes with introns in Haloxylon ammodendron and $\boldsymbol{H}$. persicum and length of exons and introns.

\begin{tabular}{llllll}
\hline & Exon I (bp) & Intron I & Exon II & Intron II & Exon III \\
\hline atpF & $145(145)$ & $785(784)$ & $410(410)$ & & \\
clpP & $71(71)$ & $951(951)$ & $292(292)$ & $601(601)$ & $228(228)$ \\
ndhA & $553(553)$ & $1090(1090)$ & $533(533)$ & & \\
ndhB & $777(777)$ & $675(675)$ & $756(756)$ & & \\
petB & $6(6)$ & $801(801)$ & $642(642)$ & & \\
petD & $8(8)$ & $722(722)$ & $475(475)$ & & \\
rpl16 & $399(399)$ & $913(913)$ & $9(9)$ & & \\
rp12 & $393(393)$ & $668(668)$ & $435(435)$ & & \\
rpoC1 & $432(432)$ & $780(780)$ & $1602(1602)$ & & \\
rps12 & $114(114)$ & - & $231(231)$ & - & \\
rps16 & $40(40)$ & $881(881)$ & $197(197)$ & & \\
trnA-UGC & $38(38)$ & $831(831)$ & $42(42)$ & & \\
trnG-GCC & $23(23)$ & $722(722)$ & $58(58)$ & & \\
trnI-GAU & $42(42)$ & $942(941)$ & $35(35)$ & & \\
trnK-UUU & $35(35)$ & $2909(2909)$ & $37(37)$ & & \\
trnL-UAA & $35(35)$ & $557(557)$ & $50(50)$ & & \\
trnV-UAC & $39(39)$ & $602(602)$ & $35(35)$ & & \\
ycf3 & $126(126)$ & $772(772)$ & $229(229)$ & $812(812)$ & \\
\hline
\end{tabular}

rps12 is trans-spliced with the 5' end located in the LSC region and the duplicated 3' end in the IR regions. 


\section{Table 3(on next page)}

Indel mutation events in the chloroplast genomes of Haloxylon ammodendron and H.persicum. 
1 Table 3 Indel mutation events in the chloroplast genomes of Haloxylon ammodendron and $\boldsymbol{H}$. persicum.

\begin{tabular}{|c|c|c|c|c|c|c|}
\hline Region & Location & Types & HA & HP & Length (bp) & Direction $^{a}$ \\
\hline$a c c \mathrm{D}-p s a \mathrm{I}$ & Intergenic & homopolymeric indel & $\mathbf{A A}$ & - & 2 & insertion \\
\hline atpA-atpF & Intergenic & homopolymeric indel & $\mathbf{T}$ & - & 1 & insertion \\
\hline $\operatorname{atpF}$ & intron & homopolymeric indel & - & $\mathbf{T}$ & 1 & deletion \\
\hline$n d h \mathrm{I}-n d h \mathrm{~A}$ & Intergenic & homopolymeric indel & - & $\mathbf{A}$ & 1 & deletion \\
\hline$n d h \mathrm{~J}-n d h \mathrm{~K}$ & Intergenic & homopolymeric indel & - & $\mathbf{T}$ & 1 & deletion \\
\hline$p s b \mathrm{I}-t r n \mathrm{~S}$ & Intergenic & homopolymeric indel & - & $\mathbf{T}$ & 1 & deletion \\
\hline$p s b \mathrm{I}-t r n \mathrm{~S}$ & Intergenic & homopolymeric indel & - & $\mathbf{A}$ & 1 & deletion \\
\hline$r b c \mathrm{~L}-a c c \mathrm{D}$ & Intergenic & homopolymeric indel & - & $\mathbf{A}$ & 1 & deletion \\
\hline rps $18-r p l 20$ & Intergenic & homopolymeric indel & $\mathbf{T}$ & - & 1 & insertion \\
\hline $\operatorname{trn} \mathrm{E}-t r n \mathrm{~T}$ & Intergenic & homopolymeric indel & - & $\mathbf{A}$ & 1 & deletion \\
\hline $\operatorname{trnK}-r p s 16$ & Intergenic & homopolymeric indel & $\mathbf{A}$ & - & 1 & insertion \\
\hline $\operatorname{trnK}$-rps 16 & Intergenic & homopolymeric indel & A & - & 1 & insertion \\
\hline $\operatorname{trn} \mathrm{L}$ & intron & homopolymeric indel & - & $\mathbf{A}$ & 1 & deletion \\
\hline $\operatorname{trn} \mathrm{L}$ & intron & homopolymeric indel & $\mathbf{A}$ & - & 1 & insertion \\
\hline $\operatorname{trn} \mathrm{L}$ & intron & homopolymeric indel & - & $\mathbf{T}$ & 1 & deletion \\
\hline $\operatorname{trn} \mathrm{R}-a p t \mathrm{~A}$ & Intergenic & homopolymeric indel & - & $\mathbf{T}$ & 1 & deletion \\
\hline atpH-atpI & Intergenic & Indel & TTATT & - & 5 & insertion \\
\hline$c l p \mathrm{P}-p s b \mathrm{~B}$ & Intergenic & Indel & - & GTCTT & 5 & deletion \\
\hline $\operatorname{pet} \mathrm{L}-p e t \mathrm{G}$ & Intergenic & Indel & - & G & 1 & deletion \\
\hline rpoB-trnC & Intergenic & Indel & - & TGTAT & 5 & deletion \\
\hline rpoB-trnC & Intergenic & Indel & TACAA & - & 5 & insertion \\
\hline$r r n 23$ & coding & Indel & - & AATTAA & 6 & deletion \\
\hline$r r n 23$ & coding & Indel & - & TTAATT & 6 & deletion \\
\hline
\end{tabular}




\section{Table 4 (on next page)}

The nucleotide substitution patterns present in the two Haloxylon chloroplast genomes. 
1 Table 4 The nucleotide substitution patterns present in the two Haloxylon chloroplast genomes.

\begin{tabular}{|c|c|c|c|}
\hline Region & Location & H. ammodendron & H.persicum \\
\hline atpA & coding & G & A \\
\hline$a t p \mathrm{I}$ & coding & $\mathbf{T}$ & $\mathrm{C}$ \\
\hline matK & coding & $\mathbf{C}$ & $\mathbf{A}$ \\
\hline$n d h \mathrm{~F}$ & coding & $\mathbf{C}$ & $\mathbf{T}$ \\
\hline$n d h \mathrm{I}$ & coding & $\mathbf{G}$ & $\mathbf{T}$ \\
\hline$p s b \mathrm{C}$ & coding & $\mathbf{A}$ & $\mathrm{C}$ \\
\hline rpoB & coding & $\mathrm{C}$ & $\mathbf{T}$ \\
\hline rpoC2 & coding & $\mathbf{C}$ & $\mathbf{A}$ \\
\hline rpoC2 & coding & $\mathrm{C}$ & $\mathbf{G}$ \\
\hline rpoC2 & coding & G & $\mathbf{T}$ \\
\hline $\operatorname{rps} 15$ & coding & $\mathbf{A}$ & G \\
\hline rps3 & coding & $\mathbf{T}$ & G \\
\hline$y c f 1$ & coding & $\mathbf{A}$ & G \\
\hline$y c f 1$ & coding & G & $\mathrm{C}$ \\
\hline$y c f 1$ & coding & G & $\mathbf{T}$ \\
\hline$a t p \mathrm{~B}-r b c \mathrm{~L}$ & Intergenic & $\mathbf{A}$ & $\mathrm{C}$ \\
\hline$a t p \mathrm{~F}-a t p \mathrm{H}$ & Intergenic & G & $\mathrm{C}$ \\
\hline$a t p \mathrm{H}-a t p \mathrm{I}$ & Intergenic & G & $\mathbf{A}$ \\
\hline$n d h \mathrm{~F}-r p l 32$ & Intergenic & G & $\mathbf{T}$ \\
\hline psaJ-rpl33 & Intergenic & $\mathrm{C}$ & $\mathbf{T}$ \\
\hline$p s a \mathrm{~J}-r p l 33$ & Intergenic & $\mathbf{T}$ & $\mathbf{A}$ \\
\hline$p s b \mathrm{E}-p e t \mathrm{~L}$ & Intergenic & $\mathrm{C}$ & $\mathbf{A}$ \\
\hline$p s b \mathrm{M}-t r n \mathrm{D}$ & Intergenic & $\mathbf{A}$ & $\mathbf{G}$ \\
\hline rpl14-rpl16 & Intergenic & $\mathbf{T}$ & G \\
\hline rpl20-rps 12 & Intergenic & G & $\mathbf{T}$ \\
\hline rpl33-rps 18 & Intergenic & $\mathbf{T}$ & $\mathrm{C}$ \\
\hline rpoA-rps 11 & Intergenic & A & G \\
\hline rpoA-rps 11 & Intergenic & $\mathbf{T}$ & $\mathrm{C}$ \\
\hline rpoB-trnC & Intergenic & G & $\mathbf{T}$ \\
\hline rpoB-trnC & Intergenic & $\mathbf{T}$ & G \\
\hline rps $18-r p l 20$ & Intergenic & $\mathbf{T}$ & G \\
\hline rps8-rpl14 & Intergenic & G & $\mathbf{A}$ \\
\hline $\operatorname{trn} \mathrm{G}-\operatorname{trn} \mathrm{R}$ & Intergenic & A & $\mathrm{C}$ \\
\hline$t r n \mathrm{H}-p s b \mathrm{~A}$ & Intergenic & $\mathbf{T}$ & $\mathbf{G}$ \\
\hline $\operatorname{trn\mathrm {K}}-m a t \mathrm{~K}$ & Intergenic & A & $\mathrm{C}$ \\
\hline $\operatorname{trn\mathrm {K}-rps16}$ & Intergenic & $\mathbf{A}$ & $\mathrm{C}$ \\
\hline trnP-psaJ & Intergenic & C & $\mathbf{T}$ \\
\hline$t r n \mathrm{P}-p s \mathrm{aJ}$ & Intergenic & C & $\mathbf{T}$ \\
\hline $\operatorname{clp} \mathrm{P}$ & intron & $\mathbf{T}$ & $\mathbf{G}$ \\
\hline$n d h \mathrm{~A}$ & intron & $\mathbf{T}$ & $\mathbf{C}$ \\
\hline rpl16 & intron & $\mathbf{T}$ & $\mathrm{C}$ \\
\hline
\end{tabular}




\begin{tabular}{llll}
$\operatorname{rps} 16$ & intron & $\mathbf{T}$ & $\mathbf{G}$ \\
$\operatorname{trn} \mathrm{V}$ & intron & $\mathbf{T}$ & $\mathbf{C}$ \\
$y c f 3$ & intron & $\mathbf{T}$ & $\mathbf{C}$ \\
\hline
\end{tabular}

2 


\section{Table 5 (on next page)}

Comparison of the mutational changes, number of transitions (Ts) and transversions $(\mathrm{TV})$, and synonymous (S) and nonsynonymous (N) substitutions per protein-coding chloroplast gene in Haloxylon ammodendron and H. persicum. 
1

2 Table 5 Comparison of the mutational changes, number of transitions (Ts) and

3 transversions ( $\mathrm{Tv}$ ), and synonymous (S) and nonsynonymous (N) substitutions per protein-coding

4 chloroplast gene in Haloxylon ammodendron and $\mathrm{H}$. persicum.

\begin{tabular}{lllll}
\hline Gene & Ts & Tv & S & $\mathbf{N}$ \\
\hline$a t p \mathrm{~A}$ & 1 & 0 & 1 & 0 \\
$a t p \mathrm{I}$ & 1 & 0 & 1 & 0 \\
$m a t \mathrm{~K}$ & 0 & 1 & 0 & 1 \\
$n d h \mathrm{~F}$ & 1 & 0 & 0 & 1 \\
$n d h \mathrm{I}$ & 0 & 1 & 0 & 1 \\
$p s b \mathrm{C}$ & 0 & 1 & 1 & 0 \\
$r p o \mathrm{~B}$ & 1 & 0 & 1 & 0 \\
$r p o \mathrm{C} 2$ & 0 & 3 & 0 & 3 \\
$r p s 15$ & 1 & 0 & 0 & 1 \\
$r p s 3$ & 0 & 1 & 0 & 1 \\
$y c f 1$ & 1 & 2 & 1 & 2 \\
Total & 6 & 9 & 5 & 10 \\
\hline
\end{tabular}

5 


\section{Table 6(on next page)}

Location of repeats in the Haloxylon ammodendron chloroplast genome. 
1 Table 6 Location of repeats in the Haloxylon ammodendron chloroplast genome.

\begin{tabular}{|c|c|c|c|c|c|}
\hline No. & Location & Motif & No. of Repeats & SSR start & SSR end \\
\hline 1 & trnK-matK & A & 11 & 1658 & 1668 \\
\hline 2 & $\operatorname{trn\mathrm {K}-rps16}$ & $\mathbf{A}$ & 12 & 4210 & 4221 \\
\hline 3 & $r p s 16-t r n \mathrm{Q}$ & $\mathbf{A}$ & 10 & 6461 & 6470 \\
\hline 4 & $\operatorname{trn} \mathrm{Q}-p s b \mathrm{~K}$ & $\mathbf{A}$ & 10 & 6957 & 6966 \\
\hline 5 & $p s b \mathrm{~K}-p s b \mathrm{I}$ & $\mathbf{A}$ & 10 & 7578 & 7587 \\
\hline 6 & $p s b \mathrm{I}-t r n \mathrm{~S}$ & $\mathbf{A}$ & 12 & 7854 & 7865 \\
\hline 7 & atp $\mathrm{F}$ intron & $\mathbf{A}$ & 10 & 12476 & 12485 \\
\hline 8 & rpo $\mathrm{C} 1$ intron & $\mathbf{A}$ & 10 & 22386 & 22395 \\
\hline 9 & $\operatorname{trn\mathrm {E}-trn\mathrm {T}}$ & $\mathbf{A}$ & 10 & 31169 & 31178 \\
\hline 10 & $\operatorname{trn} \mathrm{L}$-intron & $\mathbf{A}$ & 12 & 47464 & 47475 \\
\hline 11 & $\operatorname{trn} \mathrm{F}-n d h \mathbf{J}$ & $\mathbf{A}$ & 10 & 48982 & 48991 \\
\hline 12 & $r b c \mathrm{~L}-a c c \mathrm{D}$ & $\mathbf{A}$ & 12 & 57323 & 57334 \\
\hline 13 & $a c c \mathrm{D}-p s a \mathrm{I}$ & $\mathbf{A}$ & 10 & 59584 & 59593 \\
\hline 14 & $p s b \mathrm{~F}$ & $\mathbf{A}$ & 10 & 64309 & 64318 \\
\hline 15 & clp $\mathrm{P}$ intron & $\mathbf{A}$ & 10 & 71717 & 71726 \\
\hline 16 & pet $\mathrm{B}$ intron & $\mathbf{A}$ & 18 & 75505 & 75522 \\
\hline 17 & $n d h \mathrm{I}-n d h \mathrm{~A}$ & $\mathbf{A}$ & 10 & 118705 & 118714 \\
\hline 18 & $p s a \mathrm{~A}$ & $\mathrm{C}$ & 10 & 40165 & 40174 \\
\hline 19 & $\operatorname{trn\mathrm {K}-rps16}$ & $\mathbf{T}$ & 10 & 4464 & 4473 \\
\hline 20 & $p s b \mathrm{I}-t r n \mathrm{~S}$ & $\mathbf{T}$ & 10 & 7745 & 7754 \\
\hline 21 & trnR-atp $\mathrm{A}$ & $\mathbf{T}$ & 11 & 9948 & 9958 \\
\hline 22 & atpA-atpF & $\mathbf{T}$ & 10 & 11532 & 11541 \\
\hline 23 & atp $\mathrm{F}$ intron & $\mathbf{T}$ & 11 & 12457 & 12467 \\
\hline 24 & rps2-rpoC2 & $\mathbf{T}$ & 11 & 15957 & 15967 \\
\hline 25 & rps2-rpoC2 & $\mathbf{T}$ & 11 & 18156 & 18166 \\
\hline 26 & rpoB & $\mathbf{T}$ & 10 & 25865 & 25874 \\
\hline 27 & $\operatorname{trn} \mathrm{D}-\operatorname{trn} \mathrm{Y}$ & $\mathbf{T}$ & 10 & 30323 & 30332 \\
\hline 28 & $t r n \mathrm{~L}-t r n \mathrm{~F}$ & $\mathbf{T}$ & 10 & 48029 & 48038 \\
\hline 29 & $n d h \mathrm{~J}-n d h \mathrm{~K}$ & $\mathbf{T}$ & 10 & 49646 & 49655 \\
\hline 30 & $\operatorname{trn} \mathrm{V}$ intron & $\mathbf{T}$ & 15 & 52214 & 52228 \\
\hline 31 & $t r n \mathrm{M}-a t p \mathrm{E}$ & $\mathbf{T}$ & 10 & 52658 & 52667 \\
\hline 32 & $r b c \mathrm{~L}-a c c \mathrm{D}$ & $\mathbf{T}$ & 14 & 57377 & 57390 \\
\hline 33 & pet $\mathrm{L}-$ pet $\mathrm{G}$ & $\mathbf{T}$ & 10 & 66141 & 66150 \\
\hline 34 & $p s a \mathrm{~J}-r p l 33$ & $\mathbf{T}$ & 12 & 67499 & 67510 \\
\hline 35 & rps 18-rpl20 & $\mathbf{T}$ & 10 & 68447 & 68456 \\
\hline 36 & rpoA & $\mathbf{T}$ & 10 & 78219 & 78228 \\
\hline 37 & rps11-rpl36 & $\mathbf{T}$ & 12 & 79577 & 79588 \\
\hline 38 & rpl32-trnL & $\mathbf{T}$ & 11 & 112371 & 112381 \\
\hline 39 & $n d h \mathrm{~A}$ intron & $\mathbf{T}$ & 12 & 119581 & 119592 \\
\hline 40 & $n d h \mathrm{~A}$ intron & $\mathbf{T}$ & 10 & 119793 & 119802 \\
\hline
\end{tabular}

2 
4

5

6

7

8

\begin{tabular}{|c|c|c|c|c|c|}
\hline No. & Location & Motif & No. of Repeats & SSR start & SSR end \\
\hline 41 & $y c f 1$ & $\mathrm{~T}$ & 12 & 125285 & 125296 \\
\hline 42 & $y c f 1$ & $\mathbf{T}$ & 10 & 125890 & 125899 \\
\hline 43 & $y c f 1$ & $\mathbf{T}$ & 14 & 126895 & 126908 \\
\hline 44 & $y c f 1$ & $\mathbf{T}$ & 10 & 127195 & 127204 \\
\hline 45 & rps16-trnQ & AT & 5 & 6277 & 6286 \\
\hline 46 & $\operatorname{trnS}-\operatorname{trn} \mathrm{G}$ & AT & 5 & 8177 & 8186 \\
\hline 47 & $\operatorname{trnS}-t r n \mathrm{G}$ & AT & 5 & 8300 & 8309 \\
\hline 48 & $\operatorname{trn} \mathrm{N}-n d h \mathrm{~F}$ & TAA & 4 & 109380 & 109391 \\
\hline 49 & $p s b \mathrm{~A}-t r n \mathrm{~K}$ & TTGT & 3 & 1522 & 1533 \\
\hline 50 & matK-trnK & TTCT & 3 & 3873 & 3884 \\
\hline 51 & atpI-rps 2 & ATTA & 3 & 15121 & 15132 \\
\hline 52 & $\operatorname{trn} \mathrm{E}-t r n \mathrm{Y}$ & ATTA & 3 & 31084 & 31095 \\
\hline 53 & $a c c \mathrm{D}-p s a \mathrm{I}$ & TAAT & 4 & 59721 & 59736 \\
\hline 54 & rps $18-r p l 20$ & TTTA & 3 & 68474 & 68485 \\
\hline 55 & $c l p \mathrm{P}$ intron & TTTC & 3 & 71598 & 71609 \\
\hline 56 & $\operatorname{rrn} 23$ & AGGT & 3 & 104481 & 104492 \\
\hline 57 & $\operatorname{trn} \mathrm{L}-c \operatorname{cs} \mathrm{A}$ & $\mathrm{AACC}$ & 3 & 113312 & 113323 \\
\hline 58 & $y c f 1$ & TAAT & 3 & 124297 & 124308 \\
\hline 59 & $\operatorname{rrn} 23$ & CTAC & 3 & 131310 & 131321 \\
\hline
\end{tabular}

9 